\title{
Impacts of Electrical Line Losses Comprising Mul- ti-Distributed Generation in Distribution System
}

\author{
Surakit Thongsuk ${ }^{1}$, Atthapol Ngaopitakkul ${ }^{2}$ \\ ${ }^{1}$ Faculty of Industrial Technology, Rajabhat Rajanagarindra University, Chachoengsao, Thailand. \\ ${ }^{2}$ Department of Electrical Engineering, Faculty of Engineering, King Mongkut's Institute of Technology Ladkrabang, \\ Bangkok, Thailand \\ Email: surakit.tho@rru.ac.th, knatthap@kmitl.ac.th
}

Received April, 2013

\begin{abstract}
This paper proposes to study the impacts of electrical line losses due to the connection of distributed generators (DG) to $22 \mathrm{kV}$ distribution system of Provincial Electricity Authority (PEA). Data of geographic information systems (GIS) including the distance of distribution line and location of load being key parameter of PEA is simulated using digital simulation and electrical network calculation program (DIgSILENT) to analyze power loss of the distribution system. In addition, the capacity and location of DG installed into the distribution system is considered. The results are shown that, when DG is installed close to the substation, the electrical line losses are reduced. However, if DG capacity becomes larger and the distance between DG and load is longer, the electrical line losses tend to increase. The results of this paper can be used to create the suitability and fairness of the fee for both DG and utility.
\end{abstract}

Keywords: Electrical Loss; Distributed Generation; Distribution System; Renewable Energy

\section{Introduction}

Electricity generated by the distributed generators (DG) is increasingly becoming widespread in many countries including Thailand by getting the attention of power industry increasingly. The installation of distributed generators in the power system affects to distribution system in several issues. These issues are extensive discussions such as magnitude and direction of power flow, electrical line losses, voltage profile, power factor, and fault level. The electrical line losses are one of issues that is interested. Electrical line loss occurs when current flows through transmission and distribution systems. The magnitude of the loss depends on amount of flowing current and the line resistance. If the capacity and location of the distribution or generators optimal to the size and location of the load, it will help to reduce the real power loss in the line. However, in some cases, the capacity and location of the generator of the group and improper loading may lead to more real power loss in the line.

Based on studied research papers related to electrical loss, in the literature [1, 2], the paper discusses the sizing and installation of distributed generators to reduce power losses in the distribution system including charges that will be occurred by the power losses. The size and placement of distributed generators installed in a suitable to minimize the power loss at the distribution system is analysed in [3-7]. In the literature [8-11], their papers use a genetic algorithm, ant colony and fuzzy logic to analyze the optimal size and location for the installation of distributed generators to reduce power loss and improve the voltage in electrical system. As a result, all of the above paper, the analysis and evaluation of electrical power loss from only 1 DG are explained but these research papers have been rarely mentioned about electrical power loss from multi-distributed generators.

This paper studies the impact of multi-distributed generators (DG) when they are employed into the distribution system. The system under this study is from Provincial Electricity Authority (PEA) that is a part of Thailand's distribution system. The capacity and location of distributed generators (DG) are varied in order to analysis the electrical line loss of the system. DIgSILENT power factory is employed to simulate and analyze the electrical line loss when distributed generation (DG) is connected to $22 \mathrm{kV}$ distribution system.

\section{Electrical Line Losses Analysis [12]}

\subsection{The Analysis of Base Case}

Electrical line losses for the base or for the case where there is no DG connected to the distribution system as shown in Figure 1 can be calculated by using equation 1 .

$$
P_{\text {Loss } 1}=3 \times I_{L}^{2} \times r \times L
$$


where

$\mathrm{P}_{\text {Loss1 }}$ is electrical line losses with no DG

$r$ is line resistance (ohm per kilometer)

$\mathrm{L}$ is the distance between substation and load (kilometer)

$\mathrm{I}_{\mathrm{L}}$ is the line current $(\mathrm{A})$

\subsection{The Analysis of Losses with DG}

When the DG is included in the distribution system as shown in Figure 2, the electrical line losses are the combination of the electrical line losses occurring between substation to the DG $\left(\mathrm{P}_{\mathrm{LSG}}\right)$ and can be calculated by using equation 2 , and the electrical line losses occurring between DG to the load location $\left(\mathrm{P}_{\mathrm{LT}}\right)$ which can be calculated by using equation 3 .

$$
\begin{gathered}
P_{L S G}=\frac{r \times G}{3 V_{L}^{2}}\left(P_{L}^{2}+Q_{L}^{2}+P_{G}^{2}+Q_{G}^{2}-2 P_{L} P_{G}-2 Q_{L} Q_{G}\right) \\
P_{L T}=\frac{r \times L}{3 V_{L}^{2}}\left[\left(P_{L}^{2}+Q_{L}^{2}\right)+\left(P_{G}^{2}+Q_{G}^{2}-2 P_{L} P_{G}-2 Q_{L} Q_{G}\right)\left(\frac{G}{L}\right)\right]
\end{gathered}
$$

Thus, the total electrical line losses $\left(\mathrm{P}_{\mathrm{LGL}}\right)$ will be calculated by equation 4 .

$$
P_{L G L}=\frac{r \times\left(P_{L}^{2}+Q_{L}^{2}\right)}{3 V_{L}^{2}}(L-G)
$$

where

$\mathrm{P}_{\mathrm{G}}$ is DG real power $(\mathrm{W})$

$\mathrm{P}_{\mathrm{L}}$ is load real power $(\mathrm{W})$

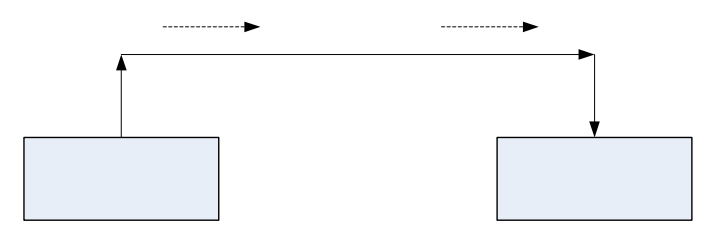

Figure 1. A simple radial system with no DG.

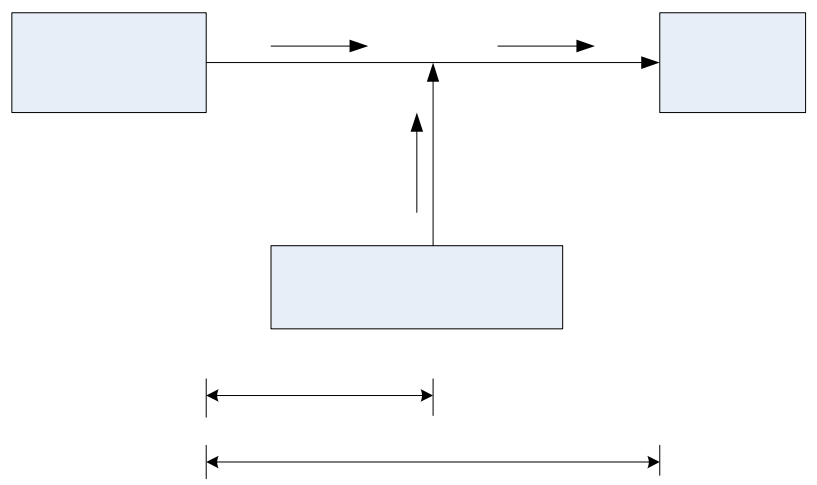

Figure 2. A simple radial system with DG connected between Substation and Load.
$\mathrm{Q}_{\mathrm{G}} \quad$ is DG reactive power (Var)

$\mathrm{Q}_{\mathrm{L}} \quad$ is load reactive power (Var)

$\mathrm{V}_{\mathrm{L}} \quad$ is load voltage

$\mathrm{G}$ is distance between substation and DG

\section{Power System Simulation using DIgSILENT}

The scheme under investigation is a part of Thailand's electricity distribution system. DIgSILENT power factory is employed to simulate and analyze the affect of electrical line losses when distributed generation (DG) is connected to $22 \mathrm{kV}$ distribution systems as shown in Figure 3. Data of geographic information systems (GIS) including the distance of distribution line and location of load that are parameters of PEA are shown in Table 1.

From Figure 3, it can be seen that there are 8 buses from substation and load of each bus that is connected between distribution lines. To study the electrical line losses, simulations were performed with various changes as follows:

- A number of distributed generators are no DG, 1 DG, and 2 DG that designated on any bus of distribution system.

- The capacity of DG is 2 MVA, 4 MVA, 6 MVA, and 8 MVA installed at the bus.

- In case of 1 DG, the DG will be moved at each bus.

- In case of 2 DG, the first DG will be installed at bus 4 and other DG will be moved at other bus.

\section{Impact of DG for Electrical line losses}

The objective of this paper is to study the impact of electrical line losses when multi-distributed generation is connected to distribution system. The power loss of the case of base case (no DG) is compared with the case of 1 DG and 2 DG. The results can be shown in Figure 4 and Figure 5, respectively.

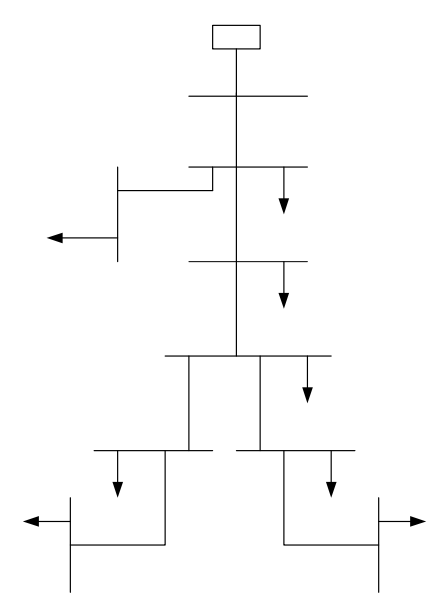

Figure 3. A simple radial system with DG connected. 
Table 1. The length of transmission line and load in each bus which is connected in distribution system.

\begin{tabular}{ccc}
\hline Bus & Distance $(\mathrm{km})$ & Load (MW) \\
\hline Substation and 1 & 4.4 & 0.14 \\
1 and 2 & 16.6 & 2.47 \\
1 and 3 & 13 & 1.11 \\
2 and 4 & 28.5 & 1.35 \\
4 and 5 & 16.87 & 1.42 \\
4 and 6 & 18 & 0.62 \\
5 and 7 & 10 & 0.58 \\
6 and 8 & 18.52 & 0.69 \\
\hline
\end{tabular}

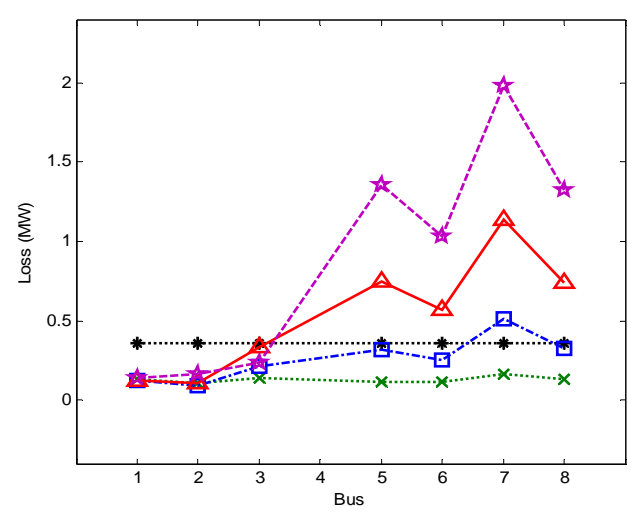

(a) Case of 2 DG that DG is 2 MVA at bus 4 .

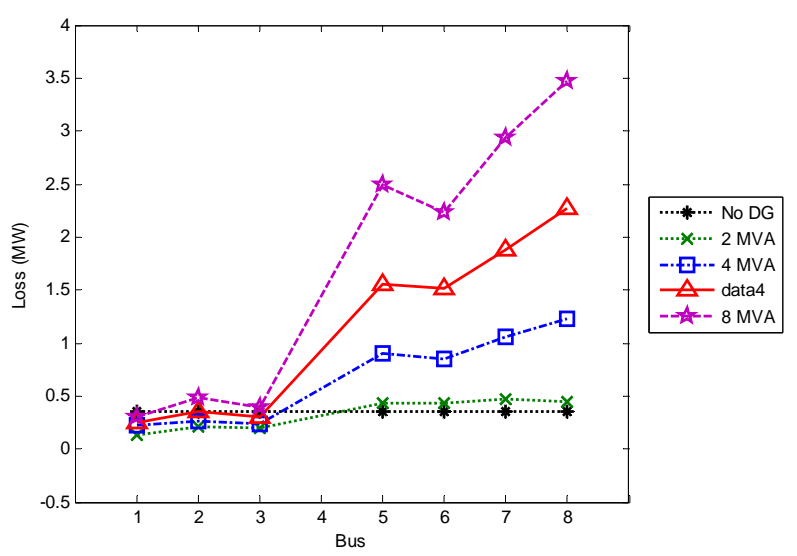

(c) Case of 2 DG that DG is 6 MVA at bus 4 .

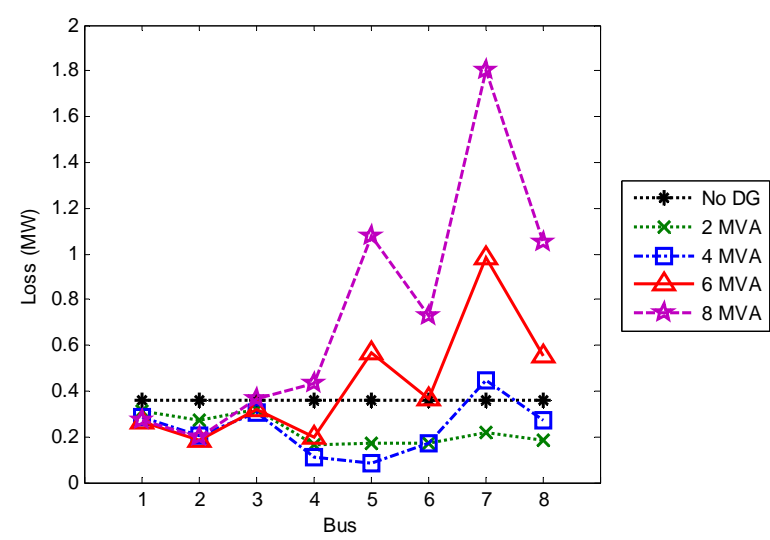

Figure 4. Electrical line losses obtained from each bus for case of no DG and with 1 DG.

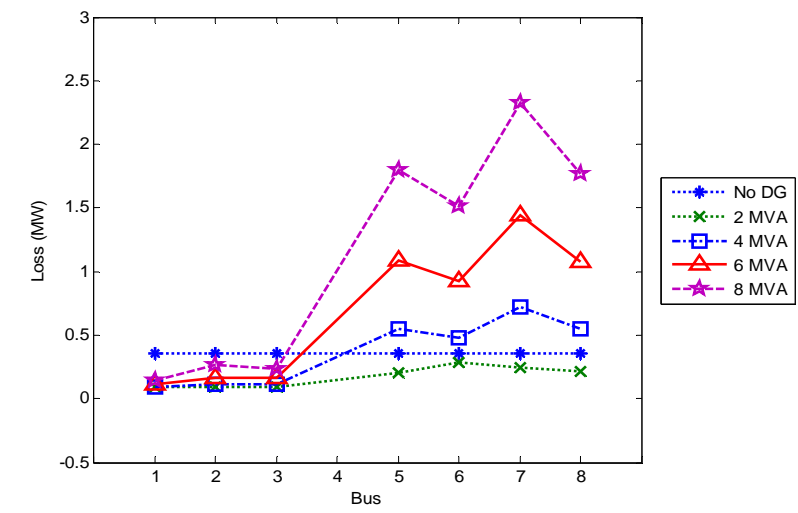

(b) Case of 2 DG that DG is 4 MVA at bus 4 .

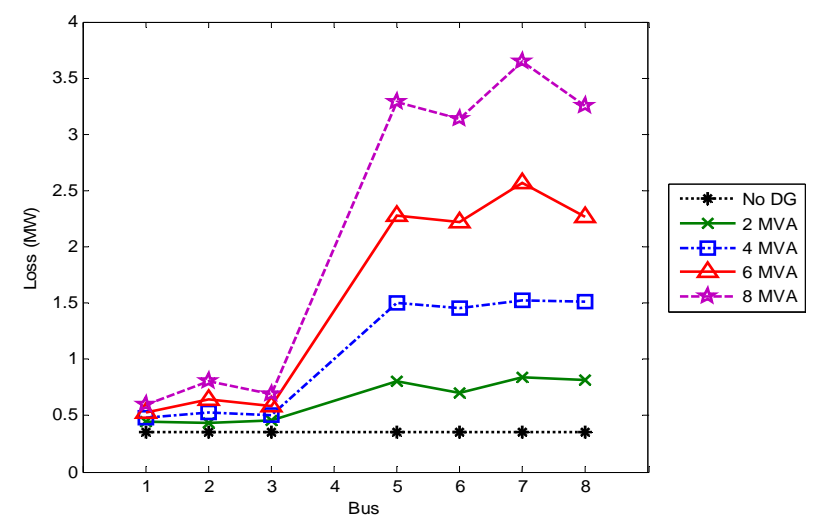

(d) Case of 2 DG that DG is 8 MVA at bus 4 .

Figure 5. Electrical line losses obtained from each bus for the case of 2 DG that DG is installed at bus 4 and other DG is installed at each bus.

The electrical line losses in case of base case (no DG) is $0.359 \mathrm{MW}$ so the electrical line losses in this case will be compared with 1 DG at each bus as shown in Figure 4 and Table 2. The comparison is divided into 4 groups of case studies. The capacity of DG installed at each bus is 2, 4, 6 and 8 MVA.

The results show that, when location of DG is at bus 1 ,
2 and 3, the electrical line losses are lower than the base case (no DG). However, when the DG is installed at bus 5 , bus 6 , bus 7 and bus 8 , it can be seen that the electrical line losses increase; this is because the size of load is less than $1 \mathrm{MW}$ and the distance from substation to load is more than $50 \mathrm{~km}$ as shown in Table 1. This indicates that utility has to be responsible for line losses. In addition, 
when capacity of DG installed at each bus is 2 MVA and 4 MVA, the electrical line losses are lower than the base case (no DG) except for the case that the capacity of DG is $4 \mathrm{MW}$ and installation location is at bus 7 which load is $0.58 \mathrm{MW}$. This indicates that utility has benefit from employing DG. When increasing the capacity of DG (4, 6 and 8 MVA) at each bus, the electrical line losses are higher than the base case (no DG) by the size and distance of load. It is noticed that, when the capacity of DG is increased, and if the DG capacity is not too large (less than 4 MVA), the electrical line losses also decrease. On the other hand, when the capacity of DG is increased and considered the load at bus 2, it can be seen that the electrical line losses are reduced for most cases because the size of load is more than $2 \mathrm{MW}$ and distance from substation to load is about $20 \mathrm{~km}$ as shown in Table 1. This also indicates that capacity of DG, location of DG, location of load and size of load play an important role for electrical line losses.

Table 2. The comparison of electrical line losses and percentage change between base case (no DG) and 1 DG.

\begin{tabular}{|c|c|c|c|c|c|c|c|c|}
\hline \multirow{3}{*}{ Bus } & \multicolumn{2}{|c|}{2 MVA } & \multicolumn{2}{|c|}{4 MVA } & \multicolumn{2}{|c|}{6 MVA } & \multicolumn{2}{|c|}{8 MVA } \\
\hline & Loss & \% Loss & Loss & $\%$ Loss & Loss & \%Loss & Loss & \%Loss \\
\hline & \multicolumn{2}{|c|}{$(\mathrm{MW})$} & \multicolumn{2}{|c|}{$(\mathrm{MW})$} & \multicolumn{2}{|c|}{$(\mathrm{MW})$} & \multicolumn{2}{|c|}{ (MW) } \\
\hline 1 & 0.31 & -13.09 & 0.283 & -21.17 & 0.268 & -25.35 & 0.27 & -24.79 \\
\hline 2 & 0.27 & -24.51 & 0.206 & -42.62 & 0.183 & -49.03 & 0.2 & -44.29 \\
\hline 3 & 0.31 & -11.42 & 0.304 & -15.32 & 0.32 & -10.86 & 0.364 & 1.39 \\
\hline 4 & 0.16 & -54.59 & 0.113 & -68.52 & 0.196 & -45.40 & 0.433 & 20.61 \\
\hline 5 & 0.17 & -51.53 & 0.085 & -76.32 & 0.565 & 57.38 & 1.072 & 198.61 \\
\hline 6 & 0.17 & -52.37 & 0.172 & -52.09 & 0.366 & 1.95 & 0.725 & 101.95 \\
\hline 7 & 0.22 & -38.44 & 0.444 & 23.68 & 0.984 & 174.09 & 1.802 & 401.95 \\
\hline 8 & 0.18 & -48.19 & 0.271 & -24.51 & 0.553 & 54.04 & 1.047 & 191.64 \\
\hline
\end{tabular}

In case of base case (no DG), it is compared with 2 DG at each bus as shown in Figure 5 and Tables 3-6. It can be seen that, the capacity of DG is 2 and 4 MVA that is installed at bus 4 and other DG is 2, 4, 6 and 8 MVA that is installed at each bus, are varied. The results show that, when other DG is located at bus 1, 2 and 3, the electrical line losses are lower than for both the base case (no DG) and the case of 1 DG at the same bus as shown in Table 3 and Table 4. However, the capacity of DG is 6 and 8 MVA that is installed at bus 4 and other DG is 2, 4, 6 and 8 MVA that is installed at each bus, are also varied. The results show that, when other DG is located at bus 1 , 2 and 3, the electrical line losses tend to increase at the same bus as shown in Table 5 and Table 6. When the other DG is installed at bus 5 , bus 6 , bus 7 and bus 8 , it can be seen that the electrical line losses increase because of the capacity of DG.
Table 3. The comparison of electrical line losses and percentage change between base case (no DG) and 2 DG that 2 MVA DG is installed at bus 4.

\begin{tabular}{|c|c|c|c|c|c|c|c|c|}
\hline \multirow{3}{*}{ Bus } & \multicolumn{2}{|c|}{2 MVA } & \multicolumn{2}{|c|}{4 MVA } & \multicolumn{2}{|c|}{6 MVA } & \multicolumn{2}{|c|}{8 MVA } \\
\hline & Loss & \%Loss & Loss & \%Loss & Loss & \%Loss & Loss & \%Loss \\
\hline & \multicolumn{2}{|c|}{ (MW) } & \multicolumn{2}{|c|}{ (MW) } & \multicolumn{2}{|c|}{$(\mathrm{MW})$} & \multicolumn{2}{|c|}{ (MW) } \\
\hline 1 & 0.133 & -62.95 & 0.12 & -66.57 & 0.123 & -65.74 & 0.143 & -60.17 \\
\hline 2 & 0.109 & -69.64 & 0.088 & -75.49 & 0.107 & -70.19 & 0.163 & -54.60 \\
\hline 3 & 0.137 & -61.84 & 0.209 & -41.78 & 0.334 & -6.96 & 0.235 & -34.54 \\
\hline 4 & 0.112 & -68.80 & 0.32 & -10.86 & 0.751 & 109.19 & 1.361 & 279.11 \\
\hline 5 & 0.118 & -67.13 & 0.251 & -30.08 & 0.567 & 57.94 & 1.036 & 188.58 \\
\hline 6 & 0.166 & -53.76 & 0.51 & 42.06 & 1.14 & 217.55 & 1.978 & 450.97 \\
\hline 7 & 0.133 & -62.95 & 0.329 & -8.36 & 0.741 & 106.41 & 1.325 & 269.08 \\
\hline 8 & 0.133 & -62.95 & 0.12 & -66.57 & 0.123 & -65.74 & 0.143 & -60.17 \\
\hline
\end{tabular}

Table 4. The comparison of electrical line losses and percentage change between base case (no DG) and 2 DG that 4 MVA DG is installed at bus 4.

\begin{tabular}{|c|c|c|c|c|c|c|c|c|}
\hline \multirow{3}{*}{ Bus } & \multicolumn{2}{|c|}{2 MVA } & \multicolumn{2}{|c|}{4 MVA } & \multicolumn{2}{|c|}{6 MVA } & \multicolumn{2}{|c|}{8 MVA } \\
\hline & Loss & \% Loss & Loss & $\%$ Loss & Loss & \% Loss & Loss & \%Loss \\
\hline & \multicolumn{2}{|c|}{ (MW) } & \multicolumn{2}{|c|}{ (MW) } & \multicolumn{2}{|c|}{ (MW) } & \multicolumn{2}{|c|}{ (MW) } \\
\hline 1 & 0.09 & -62.95 & 0.094 & -73.82 & 0.113 & -68.52 & 0.149 & -58.50 \\
\hline 2 & 0.092 & -74.37 & 0.111 & -69.08 & 0.168 & -53.20 & 0.261 & -27.30 \\
\hline 3 & 0.094 & -73.82 & 0.114 & -68.25 & 0.163 & -54.60 & 0.24 & -33.15 \\
\hline 4 & 0.203 & -43.45 & 0.546 & 52.09 & 1.09 & 203.62 & 1.801 & 401.67 \\
\hline 5 & 0.201 & -44.01 & 0.483 & 34.54 & 0.923 & 157.10 & 1.512 & 321.17 \\
\hline 6 & 0.244 & -32.03 & 0.72 & 100.56 & 1.446 & 302.79 & 2.321 & 546.52 \\
\hline 7 & 0.215 & -40.11 & 0.554 & 54.32 & 1.081 & 201.11 & 1.768 & 392.48 \\
\hline 8 & 0.09 & -62.95 & 0.094 & -73.82 & 0.113 & -68.52 & 0.149 & -58.50 \\
\hline
\end{tabular}

Table 5. The comparison of electrical line losses and percentage change between base case (no DG) and 2 DG that 6 MVA DG is installed at bus 4 .

\begin{tabular}{cccccccccc}
\hline & \multicolumn{2}{c}{2 MVA } & \multicolumn{2}{c}{ 4 MVA } & \multicolumn{2}{c}{ 6 MVA } & \multicolumn{2}{c}{ 8 MVA } \\
\cline { 2 - 9 } Bus & Loss & \% Loss & Loss & \% Loss & Loss & \% Loss & Loss & \%Loss \\
\cline { 2 - 9 } & \multicolumn{2}{c}{$(\mathrm{MW})$} & \multicolumn{2}{c}{$(\mathrm{MW})$} & $(\mathrm{MW})$ & \multicolumn{2}{c}{$(\mathrm{MW})$} \\
\hline 1 & 0.133 & 25.63 & 0.22 & -38.72 & 0.254 & -29.25 & 0.304 & -15.32 \\
2 & 0.207 & -42.34 & 0.261 & -27.30 & 0.353 & -1.67 & 0.48 & 33.70 \\
3 & 0.204 & -43.18 & 0.24 & -33.15 & 0.304 & -15.32 & 0.396 & 10.31 \\
4 & 0.439 & 22.28 & 0.903 & 151.53 & 1.554 & 332.87 & 2.497 & 595.54 \\
5 & 0.438 & 22.01 & 0.846 & 135.65 & 1.521 & 323.68 & 2.232 & 521.73 \\
6 & 0.476 & 32.59 & 1.062 & 195.82 & 1.879 & 423.40 & 2.936 & 717.83 \\
7 & 0.45 & 25.35 & 1.234 & 243.73 & 2.272 & 532.87 & 2.468 & 587.47 \\
8 & 0.133 & 25.63 & 0.22 & -38.72 & 0.254 & -29.25 & 0.304 & -15.32 \\
\hline
\end{tabular}


Table 6. The comparison of electrical line losses and percentage change between base case (no DG) and 2 DG that 8 MVA DG is installed at bus 4 .

\begin{tabular}{ccccccccc}
\hline & \multicolumn{2}{c}{ 2 MVA } & \multicolumn{2}{c}{ 4 MVA } & \multicolumn{2}{c}{ 6 MVA } & \multicolumn{2}{c}{8 MVA } \\
\cline { 2 - 8 } Bus & Loss & \% Loss & Loss & \% Loss & Loss & \% Loss & Loss & \%Loss \\
\cline { 2 - 9 } & \multicolumn{2}{c}{$(\mathrm{MW})$} & $(\mathrm{MW})$ & $(\mathrm{MW})$ & $(\mathrm{MW})$ \\
\hline 1 & 0.451 & 25.63 & 0.483 & 34.54 & 0.531 & 47.91 & 0.594 & 65.46 \\
2 & 0.437 & 21.73 & 0.525 & 46.24 & 0.648 & 80.50 & 0.807 & 124.79 \\
3 & 0.454 & 26.46 & 0.504 & 40.39 & 0.581 & 61.84 & 0.687 & 91.36 \\
4 & 0.806 & 124.51 & 1.503 & 318.66 & 2.277 & 534.26 & 3.283 & 814.48 \\
5 & 0.804 & 123.96 & 1.451 & 304.18 & 2.218 & 517.83 & 3.141 & 774.93 \\
6 & 0.84 & 133.98 & 1.528 & 325.63 & 2.567 & 615.04 & 3.652 & 917.27 \\
7 & 0.815 & 127.02 & 1.51 & 320.61 & 2.269 & 532.03 & 3.257 & 807.24 \\
8 & 0.451 & 25.63 & 0.483 & 34.54 & 0.531 & 47.91 & 0.594 & 65.46 \\
\hline
\end{tabular}

On the other hand, when the capacity of DG at bus 4 is varied and the capacity of other DG does not change, it is noticed that the electrical line losses at each bus are slightly increased more than the base case (no DG). This also indicates the slight mismatch between DG capacity and size of load.

Considering the load at bus 7 and bus 8 that is less than $1 \mathrm{MW}$ and load is installed at the end of the distribution system, it can be seen that the electrical line losses tend to increase, when the capacity of DG is increased. However, if the DG capacity is not too large (less than 4 MVA), the electrical line losses also decrease. This also indicates the slight mismatch between DG capacity and size of load. From the Figure 5(d) and Table 6, it is clearly seen that as the DG capacity increases, the electrical line losses also increases.

\section{Conclusions}

This paper presented the impact of electrical line losses when multi-distributed generation is connected to distribution system. In order to evaluate the impact of multiDG for electrical line losses, the line losses of the case of no DG and with DG are compared. The results show that when DG is installed close to the substation, the electrical line losses are reduced. However, if DG capacity becomes larger and the distance between DG and load is longer, the electrical line losses tend to increase. The results indicate that the capacity of DG, location of DG, location of load and size of load play an important role for electrical line losses as shown in Figures $\mathbf{4}$ and $\mathbf{5}$.

\section{Acknowledgements}

The authors wish to gratefully acknowledge financial support for this research from the King Mongkut's Institute of Technology Ladkrabang Research fund. And en- ergy policy and planning office (EPPO), Ministry of Energy, Thailand. They would like also to thank for the DIgSILENT presented in this paper which is supported by Provincial Electricity Authority (PEA).

\section{REFERENCES}

[1] M. A. Kashem, G. Ledwich, M. Negnevitsky and D. T. Le, "Distributed Generation for Minimization of Power Losses in Distribution Systems,” IEEE Power Engineering Society General Meeting, 2006, pp. 1-8.

[2] O. Aliman, I. Musirin and M. H. Sulaiman, "DG Sizing Impact for Loss Minimization Considering Cost Factor," 2012 IEEE International Power Engineering and Optimization Conference (PEDCO), Malaysia, 6-7 June 2012, pp. 389-394.

[3] D. Q. Hung and N. Mithulananthan, “An Optimal Operating Strategy of DG Unit for Power Loss Reduction in Distribution Systems," 7th IEEE International Conference on Industrial and Information Systems (ICIIS), 2012, pp. 1-6.

[4] Y. M. Atwa, E. F. El-Saadany, M. M. A. Salama and R. Seethapathy, "Distribution System Loss Minimization Using optimal DG mix,” IEEE Power \& Energy Society General Meeting (PES '09), 2009, pp. 1-6.

[5] M. F. Shaaban and E. F. El-Saadany, "Optimal Allocation of Renewable DG for Reliability Improvement and Losses Reduction,” IEEE Power and Energy Society General Meeting, 2012, pp. 1-8.

[6] R. K. Hosseini and R. Kazemzadeh, "Optimal DG Allocation by Extending an Analytical Method to Minimize Losses in Radial Distribution Systems," 19th Iranian Conference Electrical Engineering (ICEE), 2011, pp. 1 6.

[7] T. Gözel and M. H. Hocaoglu, "An Analytical Method for the Sizing and Siting of Distributed Generators in Radial Systems," Elect. Power Syst. Res, Vol. 79, No. 6, 2009, pp. 912-918. doi:10.1016/j.epsr.2008.12.007

[8] N. Mithulananthan, T. Oo and V. P. Le, "Distributed Generator Placement in Power Distribution System using Genetic Algorithm to Reduce Losses," TIJSAT, Vol. 9, No. 3, 2004, pp. $55-62$.

[9] F. Sheidaei, M. Shadkam and M. Zarei, “Optimal distributed generation allocation in distribution systems employing ant colony to reduce losses," 43rd International Universities Power Engineering Conference (UPEC 2008), 2008, pp. 1 - 5. doi:10.1109/UPEC.2008.4651548

[10] N. K. Aryani, M. Abdillah, I. M. Y. Negara and A. Soeprijanto, "Optimal Placement and Sizing of Distributed Generation using Quantum Genetic Algorithm for Reducing Losses and Improving Voltage Profile," IEEE Region 10 Conference (TENCON 2011), 2011, pp. 108 112.

[11] M. T. Ameli, V. Shokri and S. Shokri, "Using Fuzzy Logic \& Full Search for Distributed Generation Allocation to Reduce Losses and Improve Voltage Profile," 2010 International Conference Computer Information 
Systems and Industrial Management Applications (CISIM), 2010, pp. 626 - 630.

doi:10.1109/CISIM.2010.5643526

[12] P. Chiradeja and C. Pothisarn, "Electrical Line Losses in
Distribution System with the Inclusion of Very Small Power Producer," In Proceedings of the fifth IASTED Asian Conference on Power and Energy Systems (AsiaPES2012), Thailand, April 2012. 